\title{
A study on hydrocarbon accumulation patterns of Ordovician deep reservoir in Tahe oilfield, Tarim Basin
}

\author{
Cun-Shan Jia, Yi Gu, Ji-Wen Huang, Gui-Lin Qiao, Cheng-Lin Chu, Miao Li
}

(Wuxi Research Institute of Petroleum Geology, Research Institute of Petroleum

Exploration and Development, SINOPEC, Wuxi, Jiangsu 214126, China)

\begin{abstract}
Recently, deep hydrocarbon exploration under Ordovician epigenetic karst oil-gas reservoir has achieved an important breakthrough in Tahe area, Tarim Basin. The deep inner reservoir in the Yingshan Formation of the Lower Ordovician, like Tashen 3 well, Tuoying 1 well and Fuyuan 1 well, are 5800-7000m in depth. The comparison of the crude oil geochemical feature of the Ordovician deep inner reservoir and epigenetic karst reservoir suggests that the two oils were generated predominantly from Cambrian-Lower Ordovician marine sapropelic source rocks. Vertically, the crude oil geochemistry parameters shows that these oils are similar in low saturation, physical properties and maturity. The accumulation process of the deep and shallow reservoirs is characterized as an entity. From the areal view, the crude oil of the deep reservoir from northern of Tahe area was generated from the maturation stage of the marine source rock and generally affected by the significant later biodegradation. The main accumulation period of the north Tahe area is the late Caledonian stage. While the deep inner reservoir in the south Tuoputai area is high mature crude oil with less secondary alteration, which basically maintains the state of high mature oil and gas in the late stage. The accumulation process in Tuoputai area contains late high mature oil and gas recharge and superposition and the main accumulation stage is in the late Hercynian stage. Comprehensive analysis of the key factors controllinhbg the accumulation of the Ordovician deep inner reservoir in Tahe oilfield indicates that deep faults paly an important role in the transporting system of the petroleum and the dense limestone plays a role in hydrocarbon preservation. The evolution process of the Tashen 3 well in northern of Tahe area can be summarized as "earlier accumulation, earlier alteration, later preservation" pattern, while the reservoir in the south is "Hercynian accumulation, later oil filling, later adjustment" pattern. Overall, burial depth contributes little in hydrocarbon accumulation of carbonate reservoir. Ultra-deep reservoir is of
\end{abstract}


considerable potential to explore.

Key words: accumulation pattern; deep reservoir; Ordovician; Tahe area 